\title{
Health Related Quality of Life
} among schoolchildren aged $12-13$ years in relation to food hypersensitivity phenotypes:
a population-based study

Åsa Strinnholm ${ }^{1,4^{*}}$, Linnéa Hedman ${ }^{1,2}$, Anna Winberg ${ }^{3}$, Sven-Arne Jansson ${ }^{1}$, Viveca Lindh ${ }^{4}$ and Eva Rönmark ${ }^{1}$

\begin{abstract}
Background: While Health Related Quality of Life has been investigated among children with IgE-mediated food allergy, less is known about quality of life among children with other types of hypersensitivity to food. The aim of this study was to investigate Health Related Quality of Life (HRQL) in children with and without food hypersensitivity. Further, we compared HRQL between children with different phenotypes of food hypersensitivity.

Methods: In a large population-based cohort of schoolchildren in Northern Sweden, the parents of 2612 (96\% of invited) completed a questionnaire. All 125 (5\%) children who reported complete elimination of milk, egg, fish or wheat due to food hypersensitivity were invited to a clinical examination and 94 children participated. Of these, 75 children also completed a generic (KIDSCREEN-52) and a disease-specific HRQL questionnaire (FAQLQ-TF). Thereafter, these children were categorised into the different phenotypes: current food allergy, outgrown food allergy, and lactose intolerance. Additionally, 209 children with unrestricted diets answered the generic questionnaire.

Results: The median score of all KIDSCREEN-52 domains were above the population norm of 50 both in children with and without food hypersensitivity. No significant differences in distribution in generic or disease-specific HRQL were found between children with or without food hypersensitivity. There were no significant differences in HRQL between children with different phenotypes of food hypersensitivity. However, children with current food allergy tended to have the lowest HRQL. Further, poor HRQL defined as $\geq 75$ th percentile for the disease specific score was significantly more common in the current food allergy phenotype in the domain Emotional impact and the total FAQLQ, compared to the other phenotypes.
\end{abstract}

Conclusions: In this population-based study, 12-13 year old children reported good HRQL regardless of having food hypersensitivity or not. However, the children with the current phenotype reported lower HRQL than the other phenotypes.

Keywords: Adolescents, Food hypersensitivity, Health Related Quality of Life, Phenotypes of food hypersensitivity, Population-based cohort study

\section{Background}

Reported food hypersensitivity (FHS) is common in the Western countries. However, there are large differences in

\footnotetext{
*Correspondence: asa.strinnholm@umu.se

${ }^{1}$ Department of Public Health and Clinical Medicine, Occupational and Environmental Medicine, OLIN Unit, Umeå University, 90187 Umeå, Sweden

Full list of author information is available at the end of the article
}

prevalence between studies. In a meta-analysis investigating FHS in 51 studies, the prevalence of self-reported FHS varied from 3 to $35 \%$ due to differences in study methods, age of study populations and geographic settings [1]. The high and increasing prevalence of reported FHS $[2,3]$ may partly be attributed to an increasing awareness about FHS in the population, as well as public interest of different diets [4]. The term FHS includes food reactions of both 
immunological and non-immunological origins, and food allergy is a subgroup of FHS [5].

Elimination of foods due to FHS may negatively affect the Health Related Quality of Life (HRQL) [6]. HRQL can be defined as self-perceived health [7] since it is possible to have a chronic disease but still experience a good self-perceived HRQL. Since HRQL is individual and varies with age [6], it is suggested that when applicable, the questionnaires should be completed by the individuals themselves [8]. Usually, children are able to complete their HRQL questionnaire from the age of eight years, given that the questionnaires are age appropriate and that the child have reading skills [9]. Generic HRQL questionnaires are used for comparisons between different diseases, or between subjects with or without a disease [10]. Disease-specific questionnaires investigate HRQL related to a specific disease, e.g. food allergy [11].

The interest in HRQL in children and adolescents with food allergy has increased during the last decades, and a number of disease-specific HRQL questionnaires are now available for children [11, 12], adolescents [13, 14], and parents to children [15-18] with IgE mediated food allergy. However, there is a limited number of HRQL questionnaires available for the wider definition FHS [19, 20]. To our knowledge, no studies have explored HRQL among children with different phenotypes of FHS.

In a population-based cohort of schoolchildren, the paediatric cohort II within the Obstructive Lung Disease in Northern Sweden studies (OLIN), 5\% of the children reported complete elimination of cow's milk, hen's egg, fish or wheat due to FHS at age 11-12 years [21]. The aim of the current study was to compare HRQL among children with and without complete elimination of cow's milk, hen's egg, fish or wheat due to FHS, and to study HRQL in relation to different FHS phenotypes. Since milk, egg, fish and wheat are staple foods in Western diet, we hypothesised that avoidance of these foods would have a negative impact on HRQL.

\section{Methods}

\section{Study population}

In 2006, all children in first and second grade (aged 7-8 years) in three municipalities in Northern Sweden were invited to a longitudinal study about asthma, rhinitis, eczema and FHS [22-24]. The current study was based on a study follow-up in 2010 when the parents of 2612 (96\% of invited) children, now in ages $11-12$ years, participated in a questionnaire survey [3]. Children in two of the municipalities were also invited to skin prick testing (SPT) with ten common airborne allergens, and 1657 (86\% of invited) participated. The SPT were performed by a small group of well-trained research nurses.

\section{Parental questionnaire}

The questionnaire included the International Study of Asthma and Allergies in Childhood questions [25] with added questions about symptoms and diagnosis of atopic diseases including FHS [3, 22]. The queries about FHS included; symptoms of FHS in relation to different foods, if elimination of the culprit food was partial or complete, and whether the child had a physician-diagnosis of celiac disease.

\section{Clinical examination}

Five percent $(n=125)$ of the children reported complete elimination of cow's milk, hen's egg, fish and/or wheat due to FHS [21]. During October and November 2010, these children were invited to a clinical examination including a structured interview, specific IgE to the culprit food and a celiac screen test (tissue transglutaminase IgA antibodies) and 94 children (75\% of invited) participated [21]. The clinical examinations were performed by the same paediatric allergist (AW). At the time of the clinical examinations, 94 children, $75(80 \%$ of participants) also answered a generic HRQL questionnaire and 74 children answered a disease-specific questionnaire. In addition, a random sample of 320 children without food hypersensitivity was invited to complete the generic $\mathrm{HRQL}$ questionnaire during the same period. The questionnaire was sent by mail to the children with unrestricted diet, and 209 (65\% of invited) participated. The children were instructed to answer the questionnaire without interference of their parents. The study design and participation are presented in Fig. 1.

\section{Phenotypes of FHS}

According to the results of the clinical examination, all children were subsequently categorised into the different FHS phenotypes. Among the 75 children who also answered the HRQL questionnaire the number of children in each phenotypes were: food allergy $(n=23)$, outgrown food allergy $(\mathrm{n}=16)$ and lactose intolerance $(\mathrm{n}=33)$. Three children could not be categorised to any of the FHS groups: one child was diagnosed as having celiac disease and two children declined participation in blood sampling. The categorisation was performed by the same paediatric allergist (AW) that performed the clinical examinations. The criteria used for the categorisation are presented in a previous study [21].

\section{The generic HRQL questionnaire}

HRQL was measured using the Health-related Quality of Life Screening Instrument, KIDSCREEN-52, a generic self-report instrument for children and adolescents aged 8-18 years [10, 26]. The questionnaire 


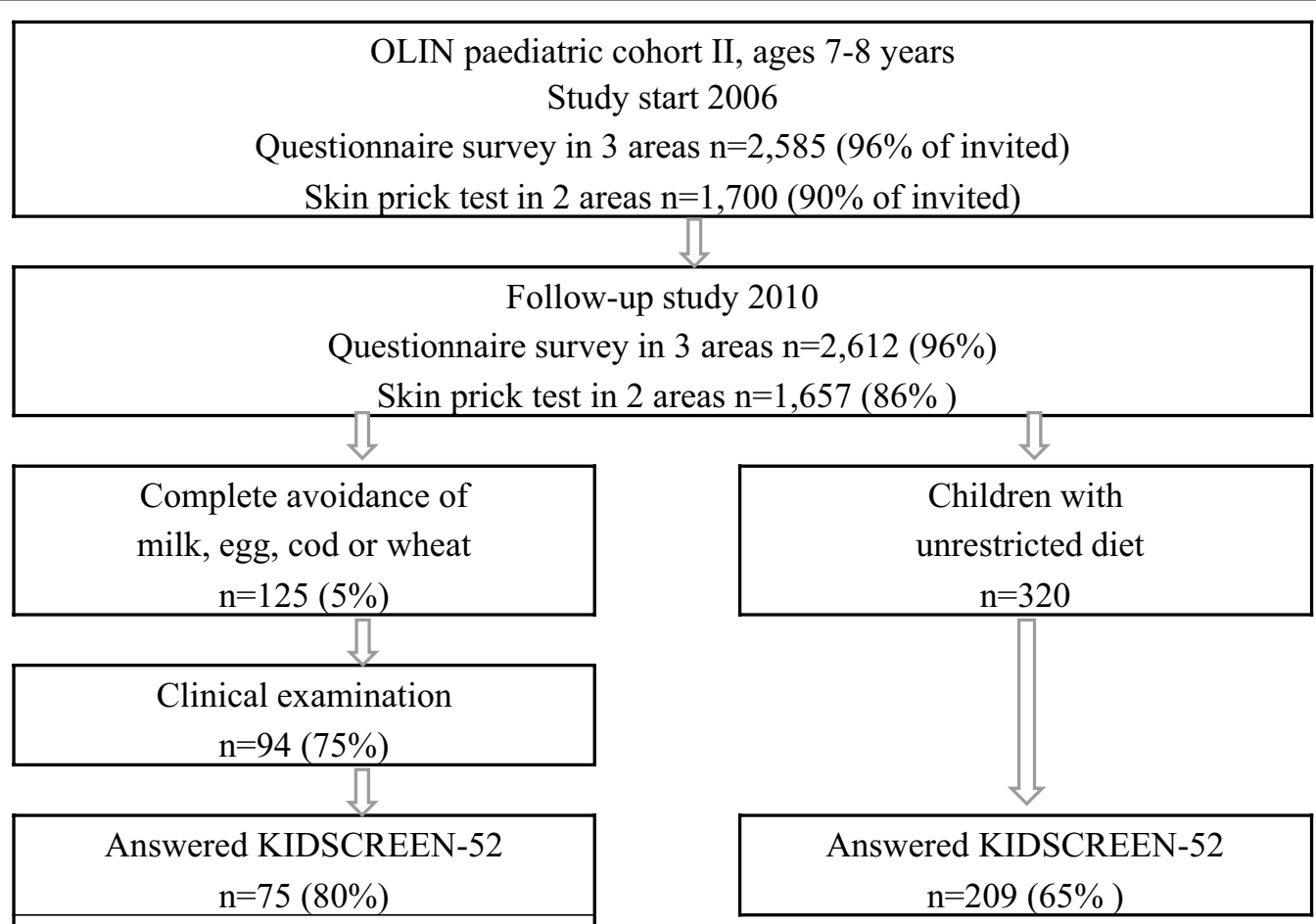

Fig. 1 Study design and participation

has predominantly been used for studies in European countries [27]. The KIDSCREEN-52 measure HRQL in ten domains with underlying items: Physical Wellbeing (five items), Psychological Well-being (six items), Moods and Emotions (seven items), Self-Perception (five items), Autonomy (five items), Parent Relation and Home Life (six items), Financial Resources (three items), Social Support and Peers (six items), School Environment (six items) and Social Acceptance and Bullying (three items). The responses are given on a five-point scale where 1 is worst HRQL and 5 is the best HRQL. The computerised data was transformed into scales from 0 to 100 for each domain [26]. The instrument, including the Swedish version, has been previously validated [27]. The population norm is a mean of 50 and a standard deviation of ten assuming a normal distributed sample is included. A higher score indicate a better HRQL with 100 indicating the best quality of life and 0 the worst $[10,26]$.

\section{The disease-specific HRQL questionnaire}

Since the children in our study were $12-13$ years of age at the time they completed the questionnaires, we used the Food Allergy Quality of Life Questionnaire Teenager
Form (FAQLQ-TF). The FAQLQ-TF questionnaire is a self-report instrument for measuring the impact of food allergy on the adolescent's HRQL, at the ages 13-17 years [13]. The FAQLQ-TF questionnaires measure HRQL in three domains with underlying items: Allergen Avoidance \& Dietary Restrictions (ten items), Risk of Accidental Exposure (six items) and Emotional Impact (seven items). The responses are given on a seven-point scale. The domain score is the sum of all question scores in the domain divided with number of completed questions in the domain. Total FAQLQ-TF score is the average score of all individual items and each score range from one (minimal impairment) to seven (maximal impairment). A higher score indicate a poorer HRQL. The questionnaire has been translated into Swedish, and used in a previous study [28] but is not yet validated in Sweden. The level of the clinical Minimal Important Difference (MID) is still undecided [29] though, a difference of $0.5-0.7$ on a seven point scale has been suggested as clinically relevant $[30$, 31].

\section{Definitions}

Any positive SPT: A positive reaction to at least one of the tested airborne allergens. 
Asthma/rhinitis/eczema: Positive response to the question: "Has the child been diagnosed by a physican as having asthma/rhinitis/eczema?"

Food hypersensitivity (FHS): Reported complete elimination of cow's milk, hen's egg, fish and/or wheat due to food allergy or food hypersensitivity.

Heredity asthma/rhinitis/eczema: Reported parental history of asthma/rhinitis/eczema.

Heredity FHS: Reported parental history of food hypersensitivity.

\section{Statistical analyses}

The statistical analyses were performed using the Statistical Package of Social Science Software version 22 (SPSS Inc. New York, USA). The Chi square test was used for comparison of categorical data. Since HRQL data was not normally distributed, the Mann-Whitney $U$ test or the Kruskal-Wallis test was used to assess statistical significant differences between groups. A $p$ value $<0.05$ was considered statistically significant. Poor HRQL was defined as $\geq 75$ th percentile for the FAQLQ-TF score and differences between groups were analyzed by Linear by linear association (Mantel-Haenszel).

\section{Results}

\section{Basic characteristics of study participants}

The prevalence of atopic diseases was significantly higher among children with FHS compared to children without FHS: asthma 25.3 versus $6.2 \%$, rhinitis 28.0 versus $6.2 \%$ and eczema 32.0 versus $10.5 \%$, as was family history of FHS, 50.7 versus $21.1 \%$ ( $p<0.001$ for all). There were no significant differences between children with and without FHS regarding allergic sensitization to airborne allergens, sex, living conditions, parental smoking or parental socio-economic status (Table 1).

The responders and non-responders to the HRQL questionnaires did not differ regarding sex, atopic diseases, heredity of FHS, allergic sensitization or living conditions. Additional files 1 and 2 shows this in more detail.

\section{Generic HRQL among children with and without FHS}

The KIDSCREEN-52 scores vary from 0 to 100, with 100 indicating the best quality of life and 0 the worst. The KIDSCREEN-52 domain specific median scores are presented in Fig. 2. The median value in all domains, among children with and without FHS were around 50 and above. No significant differences in distribution of HRQL were found when comparing children with or without FHS. In the SelfPerceptions domain, the median value tended to be lower among children with FHS compared to children without FHS, although the difference was not statistically significant.

Stratified analysis by sex were performed. Among girls, there was a significant difference between children
Table 1 Comparison of atopic diseases and demographic factors between children with and without food hypersensitivity (FHS)

\begin{tabular}{|c|c|c|c|}
\hline & $\begin{array}{l}\text { FHS } n=75 \\
\%(n)\end{array}$ & $\begin{array}{l}\text { Non-FHS } n=209 \\
\%(n)\end{array}$ & $p$ value \\
\hline \multicolumn{4}{|l|}{ Sex } \\
\hline Girls & $58.7(44)$ & $48.3(101)$ & 0.124 \\
\hline Boys & $41.3(31)$ & $51.7(108)$ & \\
\hline Asthma & $25.3(19)$ & $6.2(13)$ & $<0.001$ \\
\hline Rhinitis & $28.0(21)$ & $6.2(13)$ & $<0.001$ \\
\hline Eczema & $32.0(24)$ & $10.5(22)$ & $<0.001$ \\
\hline Heredity FHS & $50.7(38)$ & $21.1(44)$ & $<0.001$ \\
\hline Any positive $\mathrm{SPT}^{\mathrm{a}}$ & $46.3(25)$ & $33.0(69)$ & 0.069 \\
\hline \multicolumn{4}{|l|}{ Living conditions } \\
\hline \multicolumn{4}{|l|}{ Current living } \\
\hline House & $86.1(62)$ & $79.6(156)$ & \\
\hline Apartment & $13.6(10)$ & $20.4(40)$ & 0.108 \\
\hline Single parent household & $8.0(6)$ & $10.2(21)$ & 0.581 \\
\hline Father smoke & $13.5(10)$ & $13.7(28)$ & 0.967 \\
\hline Mother smoke & $10.8(8)$ & $18.2(37)$ & 0.139 \\
\hline \multicolumn{4}{|l|}{ Parental socioeconomic status } \\
\hline Professionals & $33.2(24)$ & $24.4(51)$ & \\
\hline Self employed & $4.0(3)$ & $6.2(13)$ & \\
\hline Intermediate non-manual & $26.7(20)$ & $30.6(64)$ & \\
\hline Assistant non-manual & $9.3(7)$ & $11.5(24)$ & \\
\hline Manual workers & $14.7(11)$ & $11.5(24)$ & \\
\hline Manual workers service & $8.0(6)$ & $10.0(21)$ & \\
\hline Unemployed & $1.3(1)$ & $3.3(7)$ & 0.714 \\
\hline
\end{tabular}

a Based on 54 children with food hypersensitivity and 209 children without food hypersensitivity who took part in skin prick testing

with and without FHS in the distribution of HRQL in the domain Social Acceptance and Bullying $(\mathrm{p}=0.037)$. In the other domains, no differences in distribution of HRQL were found, among neither girls nor boys (Table 2).

\section{Generic HRQL in different FHS phenotypes}

HRQL was compared between children with the different FHS phenotypes: current food allergy, outgrown food allergy and lactose intolerance. The KIDSCREEN-52 domain specific scores according to FHS phenotype are presented in Table 3. No significant differences in distribution were found between the phenotypes and the children without FHS. Children with current food allergy tended to have the lowest median values in several domains but the differences were not statistically significant.

\section{Disease specific HRQL in different FHS phenotypes}

The FAQLQ-TF responses are given on a seven-point scale where 1 is the best HRQL and 7 is the worst HRQL. 


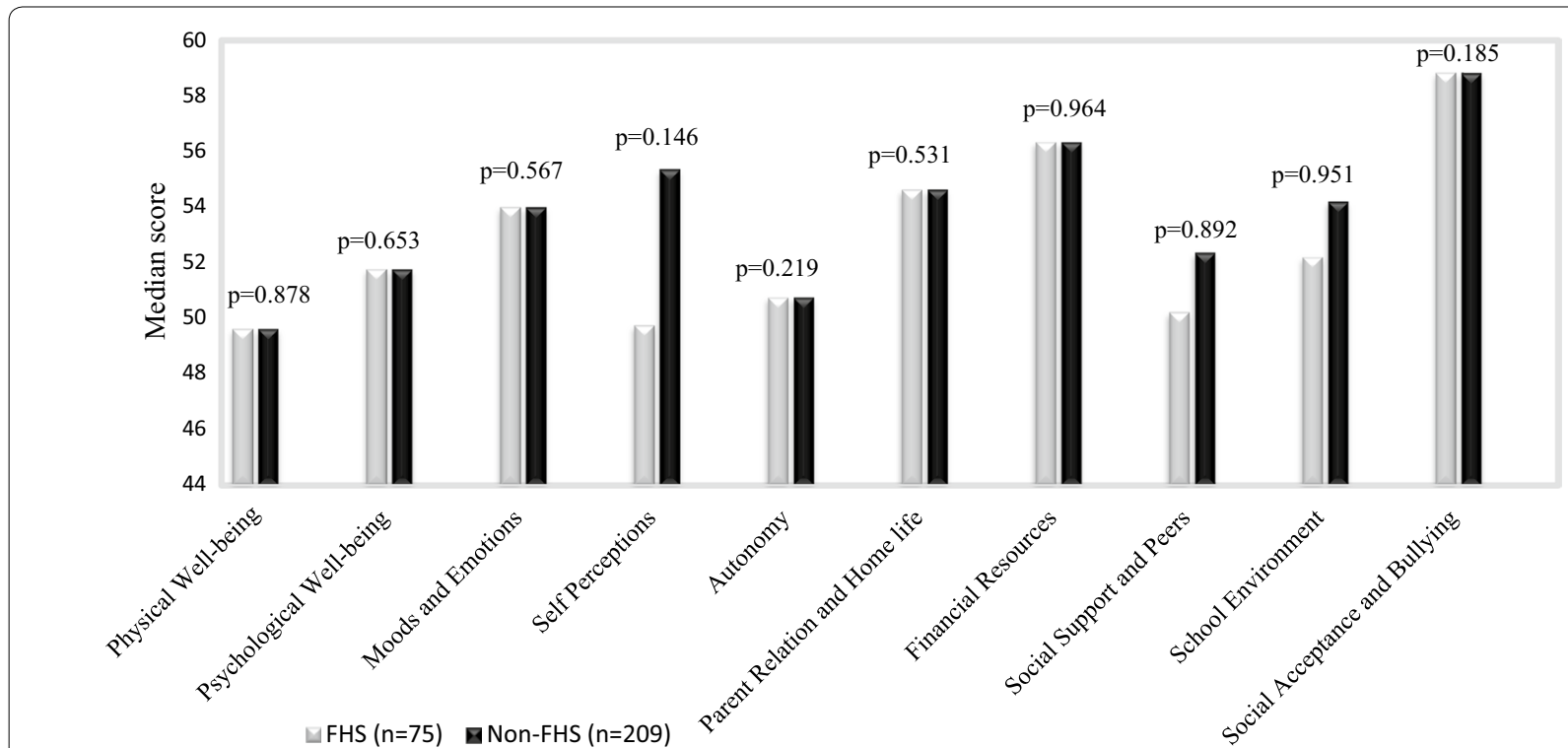

Fig. 2 Median scores in KIDSCREEN-52 domains, among children with and without food hypersensitivity. A higher score indicate better HRQL. Differences between groups was analysed by Mann-Whitney $U$ test

Table 2 Scores in KIDSCREEN-52 domains among girls and boys, with and without food hypersensitivity, respectively

\begin{tabular}{|c|c|c|c|c|c|c|}
\hline \multirow{2}{*}{ KIDSCREEN-52 dimension } & \multicolumn{3}{|l|}{ Girls } & \multicolumn{3}{|l|}{ Boys } \\
\hline & $\begin{array}{l}\text { FHS }(n=44) \\
\text { Median }\left(Q_{1}-Q_{3}\right) \\
\text { Mean }\end{array}$ & $\begin{array}{l}\text { Non-FHS }(n=101) \\
\text { Median }\left(Q_{1}-Q_{3}\right) \\
\text { Mean }\end{array}$ & p value* & $\begin{array}{l}\text { FHS }(n=31) \\
\text { Median }\left(Q_{1}-Q_{3}\right) \\
\text { Mean }\end{array}$ & $\begin{array}{l}\text { Non-FHS }(n=108) \\
\text { Median }\left(Q_{1}-Q_{3}\right) \\
\text { Mean }\end{array}$ & p value* \\
\hline \multirow[t]{2}{*}{ Physical well-being } & $49.6(42.5-58.4)$ & $49.6(42.5-55.6)$ & 0.641 & $49.6(44.7-52.4)$ & $49.6(44.7-59.3)$ & 0.521 \\
\hline & 50.1 & 49.5 & & 50.1 & 51.0 & \\
\hline \multirow[t]{2}{*}{ Psychological well-being } & $51.8(47.1-56.8)$ & $51.7(45.1-57.6)$ & 0.447 & $51.8(45.1-57.6)$ & $54.5(47.1-57.6)$ & 0.172 \\
\hline & 53.2 & 51.6 & & 51.8 & 53.8 & \\
\hline \multirow[t]{2}{*}{ Moods and emotions } & $50.2(45.4-62.1)$ & $54.0(45.4-62.1)$ & 0.702 & $54.0(47.1-70.9)$ & $55.7(49.1-62.1)$ & 0.982 \\
\hline & 52.9 & 53.5 & & 55.35 & 56.5 & \\
\hline \multirow[t]{2}{*}{ Self perceptions } & $49.8(46.1-56.6)$ & $52.2(45.3-60.1)$ & 0.879 & $52.2(49.8-69.8)$ & $55.4(52.2-60.1)$ & 0.199 \\
\hline & 52.7 & 52.8 & & 55.8 & 57.6 & \\
\hline \multirow[t]{2}{*}{ Autonomy } & $48.7(45.2-60.5)$ & $50.7(47.8-56.3)$ & 0.879 & $53.2(46.8-60.5)$ & $53.2(48.7-60.5)$ & 0.646 \\
\hline & 51.8 & 53.6 & & 52.8 & 54.6 & \\
\hline \multirow[t]{2}{*}{ Parent relation and home life } & $54.6(48.0-58.5)$ & $54.6(47.5-65.9)$ & 0.691 & $54.6(47.5-65.9)$ & $54.6(49.5-65.9)$ & 0.759 \\
\hline & 53.8 & 54.3 & & 54.3 & 55.4 & \\
\hline \multirow[t]{2}{*}{ Financial resources } & $56.3(49.3-62.9)$ & $56.3(49.3-62.9)$ & 0.945 & $56.3(46.6-62.9)$ & $56.3(49.3-62.9)$ & 0.942 \\
\hline & 55.6 & 55.8 & & 55.3 & 55.4 & \\
\hline \multirow[t]{2}{*}{ Social support and peers } & $52.4(48.3-58.1)$ & $54.9(47.1-58.1)$ & 0.667 & $48.3(45.1-58.1)$ & $50.2(45.1-58.1)$ & 0.828 \\
\hline & 53.8 & 54.1 & & 51.5 & 51.8 & \\
\hline \multirow[t]{2}{*}{ School environment } & $54.2(50.4-61.9)$ & $54.2(48.6-61.9)$ & 0.905 & $52.2(46.9-58.9)$ & $52.2(48.6-56.4)$ & 0.660 \\
\hline & 55.7 & 56.0 & & 53.1 & 53.1 & \\
\hline \multirow[t]{2}{*}{ Social acceptance and bullying } & $58.8(48.1-58.8)$ & $58.8(58.8-58.8)$ & 0.037 & $58.8(48.1-58.8)$ & $58.8(48.1-58.8)$ & 0.947 \\
\hline & 52.6 & 55.7 & & 52.6 & 52.6 & \\
\hline
\end{tabular}

* The statistical significant differences between groups was measured by Mann-Whitney U test 
Table 3 Scores in KIDSCREEN-52 domains among children with different food hypersensitivity phenotypes and children without food hypersensitivity

\begin{tabular}{|c|c|c|c|c|c|}
\hline KIDSCREEN-52 dimension & $\begin{array}{l}\text { Current food allergy } \\
\mathrm{n}=23 \\
\text { Median (Q1-Q3) } \\
\text { Mean }\end{array}$ & $\begin{array}{l}\text { Outgrown food allergy } \\
\mathrm{n}=16 \\
\text { Median (Q1-Q3) } \\
\text { Mean }\end{array}$ & $\begin{array}{l}\text { Lactose intolerance } \\
\mathrm{n}=33 \\
\text { Median (Q1-Q3) } \\
\text { Mean }\end{array}$ & $\begin{array}{l}\text { Non-FHS } \\
\mathrm{n}=209 \\
\text { Median (Q1-Q3) } \\
\text { Mean }\end{array}$ & $\begin{array}{l}\text { p value } \\
\text { Across } \\
4 \text { groups* }\end{array}$ \\
\hline \multirow[t]{2}{*}{ Physical well-being } & $47.08(42.53-55.60)$ & $49.63(40.97-63.06)$ & $49.63(44.73-55.60)$ & $49.63(43.08-55.60)$ & 0.896 \\
\hline & 48.87 & 51.46 & 50.49 & 50.29 & \\
\hline \multirow[t]{2}{*}{ Psychological well-being } & $49.34(45.10-54.49)$ & $54.49(44.21-68.49)$ & $54.49(47.12-68.49)$ & $51.78(47.12-57.60)$ & 0.321 \\
\hline & 49.22 & 53.98 & 54.79 & 52.79 & \\
\hline \multirow[t]{2}{*}{ Moods and emotions } & $51.34(42.50-62.06)$ & $57.39(47.64-70.90)$ & $54.02(47.15-62.06)$ & $54.02(47.15-62.06)$ & 0.369 \\
\hline & 49.94 & 57.24 & 55.65 & 55.07 & \\
\hline \multirow[t]{2}{*}{ Self perceptions } & $49.76(46.09-60.11)$ & $52.18(47.78-69.78)$ & $50.97(48.28-58.93)$ & $55.38(49.76-60.11)$ & 0.593 \\
\hline & 53.54 & 55.42 & 54.26 & 55.27 & \\
\hline \multirow[t]{2}{*}{ Autonomy } & $48.69(40.54-56.27)$ & $53.33(45.17-60.52)$ & $53.22(46.85-68.75)$ & $50.77(48.69-60.52)$ & 0.211 \\
\hline & 48.65 & 53.33 & 55.09 & 54.15 & \\
\hline \multirow[t]{2}{*}{ Parent relation and home life } & $54.65(47.50-60.36)$ & $56.58(46.17-65.87)$ & $54.65(47.50-58.53)$ & $54.65(47.50-65.87)$ & 0.928 \\
\hline & 53.25 & 55.03 & 54.33 & 54.88 & \\
\hline \multirow[t]{2}{*}{ Financial resources } & $62.86(46.59-62.87)$ & $52.41(47.26-62.86)$ & $59.60(53.39-62.86)$ & $56.35(49.27-62.86)$ & 0.537 \\
\hline & 55.74 & 53.93 & 56.75 & 55.55 & \\
\hline \multirow[t]{2}{*}{ Social support and peers } & 48.35 (46.66-54.93) & $49.30(44.37-57.33)$ & $54.93(47.50-67.06)$ & $52.38(46.66-58.13)$ & 0.463 \\
\hline & 50.96 & 51.39 & 55.30 & 52.88 & \\
\hline \multirow[t]{2}{*}{ School environment } & $52.23(46.94-58.87)$ & $56.55(52.22-61.87)$ & $52.22(48.61-61.87)$ & $54.22(48.61-58.87)$ & 0.758 \\
\hline & 53.46 & 56.11 & 55.00 & 54.82 & \\
\hline \multirow[t]{2}{*}{ Social acceptance and bullying } & $58.85(42.19-58.85)$ & $58.85(48.07-58.85)$ & $58.85(48.07-58.85)$ & $58.85(48.07-58.85)$ & 0.556 \\
\hline & 50.93 & 53.22 & 53.99 & 54.12 & \\
\hline
\end{tabular}

* The statistical significant differences between groups was measured by the Kruskal-Wallis test

The FAQLQ-TF domain specific scores are presented in Fig. 3. No statistically significant differences in distribution of disease specific HRQL score were found between the different FHS phenotypes. However, the median score in all domains tended to be highest (indicating low HRQL) among children with current food allergy compared to outgrown food allergy and lactose intolerance phenotypes. Mean and median scores in FAQLQ-TF domains did not differ significantly by sex (Additional file 3).

The proportions of poor HRQL, defined as $\geq 75$ th percentile are presented in Fig. 4. Poor HRQL was most common among children with current food allergy, and significantly so in the domain Total FAQLQ-score $(\mathrm{p}=0.045)$ and Emotional Impact $(\mathrm{p}<0.001)$.

\section{Discussion}

According to European norms [10,26], the children aged 12-13 years in this population-based study reported a good generic HRQL and there was no difference in HRQL between children with and without FHS. Further, no statistically significant differences in disease specific HRQL were found between children with the different FHS phenotypes: current food allergy, outgrown food allergy and lactose intolerance. However, the proportion of children having poor quality of life, defined as $\geq 75$ th percentile in the disease specific questionnaire, was more common in the current food allergy phenotype compared to the other phenotypes of FHS.

The participants in our study reported a good generic HRQL. Our result is in line with another Swedish population-based study comparing children aged eight years with or without atopic diseases including FHS. Overall, these children reported a good generic HRQL but children with atopic diseases, in particular asthma, had lower HRQL compared with children without atopic diseases [32]. Other factors than the disease itself may have an impact on the HRQL e.g. parental income [33], or being accepted by friends or not [34]. A possible explanation for the good HRQL among children with FHS in our study, and others as well, may be that FHS is common among children in Northern Europe [35]. Thus living with FHS or food allergy might be accepted as a normality and the restricted diet might therefore have a lesser impact on children's daily life [36, 37].

The increased availability of milk and gluten free products in Sweden may affect the HRQL in a positive way e.g. it is easier to prepare meals for children with 


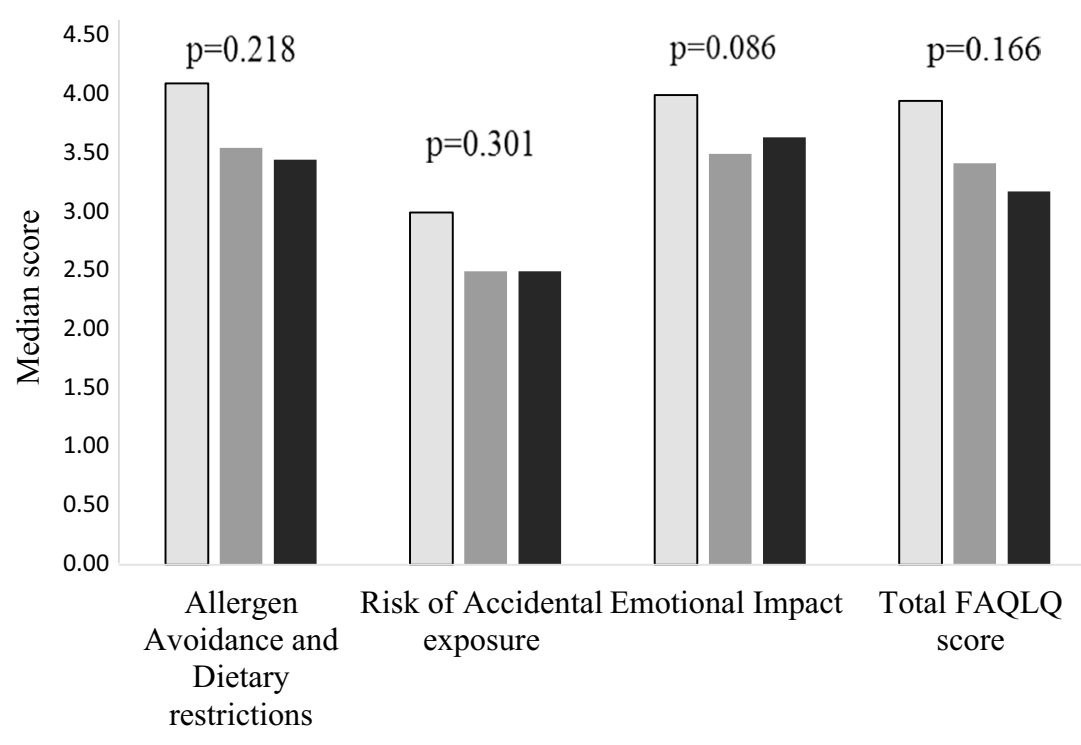

$\square$ Current food allergy $(\mathrm{n}=23) \quad$ Outgrown food allergy $(\mathrm{n}=16) \quad$ Lactose intolerance $(\mathrm{n}=32)$

Fig. 3 Median scores in FAQLQ-TF domains, by food hypersensitivity phenotypes. A higher score indicate a poorer HRQL. Differences between groups was analysed by the Kruskal-Wallis test. The score range of FAQLQ-TF is between 1 (best HRQL) and 7 (worst HRQL)

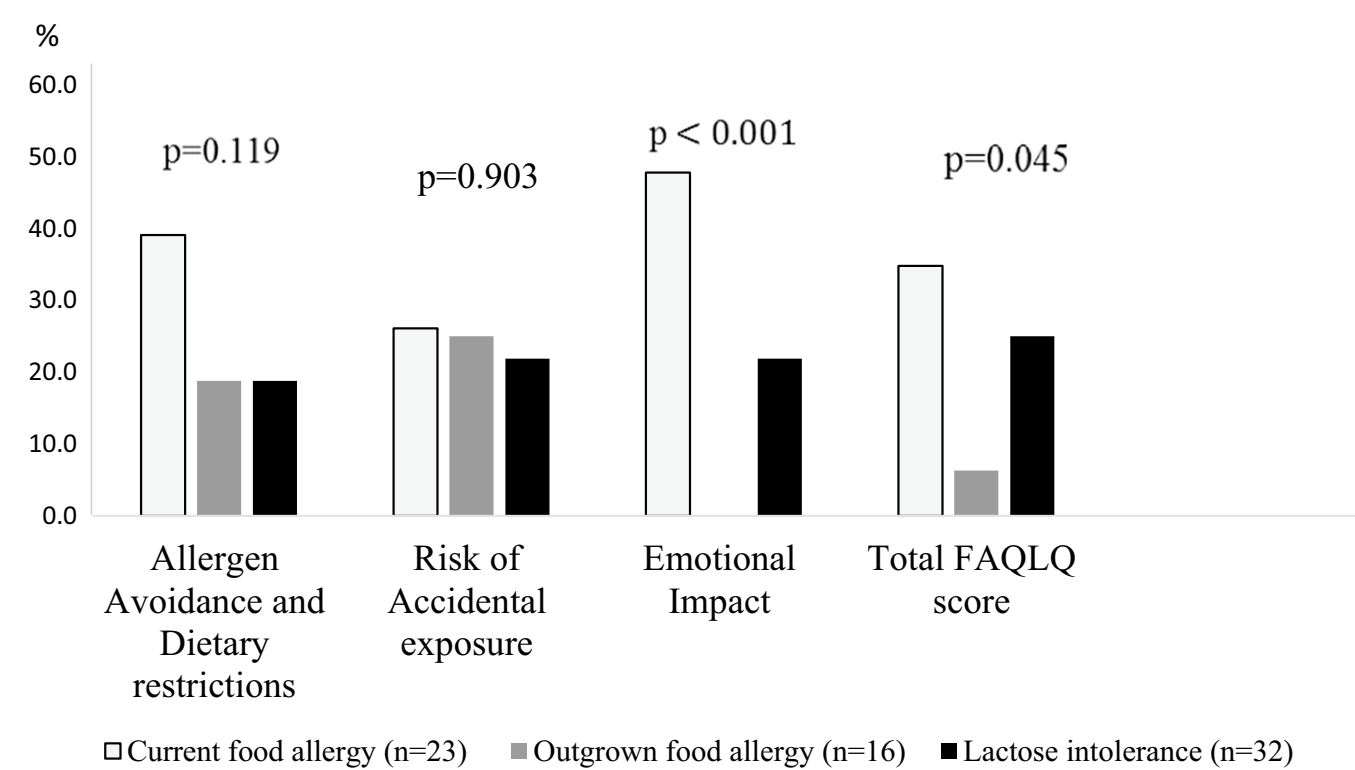

Fig. 4 Prevalence (\%) of poor HRQL ( $\geq 75$ percentile) in FAQLQ-TF domains by food hypersensitivity phenotypes. A higher score indicate a poorer HRQL. Difference between groups was analysed by Linear by linear association (Mantel-Haenszel)

different types of FHS. On the other hand, it probably also increases the awareness of different types of diets. People may regard temporary or non-specific symptoms as symptoms of FHS leading to an un-necessary eliminated diet [4]. Interestingly, the participants in our study showed similar results compared to a Swedish study of randomly selected children aged 11-16 years, with the lowest score in the domain Physical wellbeing [38].

Country of origin may have an impact of HRQL. The Food Allergy Quality of Life Questionnaire-parent form was completed by parents of 1029 food allergic children from different parts of the US. The result was compared 
with 15 studies from different countries in Europe, using the same questionnaire. The HRQL was more impaired in the US population than the European populations [39]. Thus, it is important that translation and validation of HRQL questionnaires includes lingual as well as cultural translations, due to socioeconomic and cultural differences between countries [40].

To our knowledge, this is the first study investigating HRQL among different phenotypes of FHS in the general population. A number of hospital-based studies have described quality of life in children with IgE-mediated food allergy [13, 33, 41]. In hospital materials, poor HRQL has been related to severe symptoms to foods e.g. anaphylaxis, respiratory or cardiovascular symptoms [33, 41], multiple food allergies [11, 33, 41], comorbidity with atopic diseases [41] or allergy to specific foods e.g. cow's milk and hen's egg compared to allergy to peanuts or tree nuts [33]. In our population-based study, we did not find any statistical significant differences in HRQL between children with and without FHS, which includes a number of different adverse reactions to foods, including food allergy [5]. Food allergy is rarely associated with mortality [42] or daily physical food related symptoms, but the psychological stress of accidently being exposed to the culprit food can be a burden $[6,43]$. Many children with FHS do not seek health care due to mild symptoms to foods [44]. Thus, it is likely that those who seek health care due to FHS have more severe symptoms and/or experience a higher impact on their daily life compared to those who do not [45]. This could explain the differing results in HRQL between hospital- based and our population-based study.

In analyses stratified by sex, we found no statistically significant differences in HRQL, except in the domain Social Acceptance and Bullying. In this domain, HRQL was more impaired among girls with FHS compared to girls without FHS, but this difference was not found among boys. It has been shown that adolescent girls generally experience a poorer HRQL compared to boys [46] which is in line with our results. Even though FHS is common among children, it may affect social life and create social exclusion [36] which may lead to bullying. In a previous study, children reported that they had been bullied because of their food allergy, mainly by classmates but also by teachers and school staff [34].

The clinical Minimal Important Difference of the disease specific FAQLQ is not yet decided [29]. We defined poor disease specific HRQL as $\geq 75$ th percentile and it was most common among children with current food allergy. A possible explanation is that severe symptoms are most common in this phenotype. While respiratory, cardiovascular and severe skin- and gastrointestinal symptoms are relatively common in food allergy [21, 41], lactose intolerance present with milder bowel symptoms [47]. Thus, children with current food allergy are probably more afraid of food reactions compared to children with other phenotypes of FHS associated with milder symptoms.

Interestingly, poor HRQL was also found among children with outgrown food allergy. This was however not surprising since these children had a convincing history of food allergy, but they still avoided the culprit food despite tolerance had been achieved [21]. It is well known that tolerance development is common in allergies to foods like egg and milk [48], but children may remain on an elimination diet even if tolerance is achieved [49]. Among our children with FHS, lactose intolerance was the most common phenotype, and these children also reported total elimination to cow's milk [21]. Studies indicate that adolescents with lactose intolerance can drink smaller amounts of cow's milk without symptoms [50]. Hence, after participating in our research program some of the children with FHS could reintroduce the eliminated food, partially or completely [21, 51] which may improve their HRQL. Reasons for staying on a restricted diet are fear of food reactions, difficulties to tolerate taste and textures of the eliminated food and unwillingness to change an approach to food that has become normality $[51,52]$. Since reported FHS is common in the population [3, 35] a correct diagnosis and follow-ups is important in order to evaluate persistence of FHS. This evaluation could be performed within the school health care in early school age [53].

\section{Strengths and limitations}

The strength of our study is that we compared HRQL between children with and without FHS in the same large population-based cohort and by using both generic and disease-specific HRQL questionnaires. By using generic HRQL questionnaire it was possible to compare HRQL among children with FHS and without FHS [54]. Because the classification of children into different FHS phenotypes was performed after completion of the HRQL questionnaire, the children's responses were not affected by receiving a new diagnosis. Another strength is that the children answered the HRQL questionnaire themselves, since disagreement between child and parent-proxy have been reported [55]. A limitation is that the disease specific questionnaire FAQLQ-TF is primarily developed for IgE-mediated food allergy [13] and does not cover other subgroups of FHS. The Swedish FAQLQ-TF version has not yet been validated but has been used in a previous Swedish study [28]. Regardless, FAQLQ-TF was used in our study because, to our knowledge, there is no available questionnaire in Swedish that is designed to describe adolescents' own perspective of living with FHS. Despite 
the current study was based on a large population-based cohort with extremely high participation rate, we were lacking power for some analyses. Regarding the diseasespecific HRQL, we found trends with those having current food allergy reporting the lowest HRQL although the differences did not reach statistical significance. Furthermore, the sample size did not allow analyses of HRQL in relation to number of foods avoided.

\section{Conclusions}

We hypothesised that total avoidance of milk, egg, fish or wheat due to food hypersensitivity would have a negative impact on HRQL in children, though this could not be verified. Instead, HRQL was similar in 12-13 year-old children with and without FHS in this population-based study. Poor HRQL was most common in the current food allergy phenotype in the domain Emotional impact and the total FAQLQ. Our study emphasizes the importance of identifying children with current food allergy, the FHS phenotype having impaired HRQL.

\section{Additional files}

Additional file 1. Characteristic of participants and non-participants with food hypersensitivity.

Additional file 2. Characteristic of participants and non-participants without food hypersensitivity.

Additional file 3. Mean and median scores in FAQLQ-TF domains among children with food hypersensitivity and by sex.

\section{Abbreviations \\ FAQLQ-TF: Food Allergy Quality of Life Questionnaire Teenager Form; FHS: food hypersensitivity; HRQL: Health Related Quality of Life; IgE: immunoglobulin E; IQ: interquartile range; KIDSCREEN-52: Health-Related Quality of Life Screening instrument for children and adolescents; MID: clinical minimal important dif- ference; SPT: skin prick testing.}

\section{Authors' contributions}

$\AA$ As, ER, VL, LH and AW contributed to the study design. ÅS, AW, ER, VL S-AJ and $\mathrm{LH}$ contributed to the analysis and interpretation of data. All authors were involved in the discussions and contributed to writing the manuscript. All authors read and approved the final manuscript.

\section{Author details}

${ }^{1}$ Department of Public Health and Clinical Medicine, Occupational and Environmental Medicine, OLIN Unit, Umeå University, 90187 Umeå, Sweden.

${ }^{2}$ Division of Nursing, Department of Health Sciences, Luleå University of Technology, 97187 Luleå, Sweden. ${ }^{3}$ Department of Clinical Sciences, Pediatrics, Umeå University, 90187 Umeå, Sweden. ${ }^{4}$ Department of Nursing, Umeå University, 90187 Umeå, Sweden.

\section{Acknowledgements}

Our deepest gratitude to the children and their parents for participating in this study.

\section{Competing interests}

The authors declare that they have no competing interests.

\section{Availability of data and materials}

All data generated and analysed during this study are included in this published article and its supplementary information files.

\section{Ethical approval and consent to participate}

The study was approved by the Regional Ethical Review Board in Umeå, Sweden D-nr 2010-247-311 and 2011-206-31M. Informed written consent was obtained from parents or proxy and assent from the children.

\section{Funding}

Financial support was provided from the Swedish Heart and Lung Foundation; Swedish Asthma and Allergy Foundation; Visare Norr; a regional agreement among Umeå University, Västerbotten, and Norrbotten Country Council (ALF); State Government Funding for Healthcare Research (FOU); The Swedish Society for Asthma and Allergy Nursing; The Sven Jerring Foundation; The Mayflower Charity Foundation for Children and The Kempe-Carlgrenska Foundation.

\section{Publisher's Note}

Springer Nature remains neutral with regard to jurisdictional claims in published maps and institutional affiliations.

Received: 14 December 2016 Accepted: 31 May 2017

Published online: 03 July 2017

\section{References}

1. Rona RJ, Keil T, Summers C, Gislason D, Zuidmeer L, Sodergren E, et al. The prevalence of food allergy: a meta-analysis. J Allergy Clin Immunol. 2007;120:638-46.

2. Nwaru BI, Hickstein L, Panesar SS, Muraro A, Werfel T, Cardona V, et al. The epidemiology of food allergy in Europe: a systematic review and metaanalysis. Allergy. 2014;69:62-75.

3. Winberg A, Strinnholm A, Hedman L, West CE, Perzanowski MS, Ronmark E. High incidence and remission of reported food hypersensitivity in Swedish children followed from 8 to 12 years of age-a population based cohort study. Clin Transl Allergy. 2014;4:32.

4. Moore LR. "But we're not hypochondriacs": the changing shape of gluten-free dieting and the contested illness experience. Soc Sci Med. 2014;105:76-83.

5. Johansson SG, Bieber T, Dahl R, Friedmann PS, Lanier BQ, Lockey RF, et al. Revised nomenclature for allergy for global use: report of the Nomenclature Review Committee of the World Allergy Organization, October 2003. J Allergy Clin Immunol. 2004;113:832-6.

6. Saleh-Langenberg J, Goossens NJ, Flokstra-de Blok BM, Kollen BJ, van der Meulen GN, Le TM, et al. Predictors of health-related quality of life of European food-allergic patients. Allergy. 2015;70:616-24.

7. Karimi M, Brazier J. Health, health-related quality of life, and quality of life: What is the difference? Pharmacoeconomics. 2016;34:645-9.

8. Slevin ML, Plant H, Lynch D, Drinkwater J, Gregory WM. Who should measure quality of life, the doctor or the patient? Br J Cancer. 1988;57:109-12.

9. Riley AW. Evidence that school-age children can self-report on their health. Ambul Pediatr. 2004;4:371-6.

10. Ravens-Sieberer U, Gosch A, Rajmil L, Erhart M, Bruil J, Duer W, Auquier P, et al. KIDSCREEN-52 quality-of-life measure for children and adolescents. Expert Rev Pharmacoecon Outcomes Res. 2005;5:353-64.

11. Flokstra-de Blok BM, DunnGalvin A, Vlieg-Boerstra BJ, Oude Elberink JN, Duiverman EJ, Hourihane JO, et al. Development and validation of a selfadministered Food Allergy Quality of Life Questionnaire for children. Clin Exp Allergy. 2009;39:127-37.

12. Avery NJ, King RM, Knight S, Hourihane JO. Assessment of quality of life in children with peanut allergy. Pediatr Allergy Immunol. 2003;14:378-82.

13. Flokstra-de Blok BM, DunnGalvin A, Vlieg-Boerstra BJ, Oude Elberink JN, Duiverman EJ, Hourihane JO, et al. Development and validation of the self-administered Food Allergy Quality of Life Questionnaire for adolescents. J Allergy Clin Immunol. 2008;122:139-44.

14. Resnick ES, Pieretti MM, Maloney J, Noone S, Munoz-Furlong A, Sicherer $\mathrm{SH}$. Development of a questionnaire to measure quality of life in adolescents with food allergy: the FAQL-teen. Ann Allergy Asthma Immunol. 2010;105:364-8. 
15. Cohen BL, Noone S, Munoz-Furlong A, Sicherer SH. Development of a questionnaire to measure quality of life in families with a child with food allergy. J Allergy Clin Immunol. 2004;114:1159-63.

16. Bollinger ME, Dahlquist LM, Mudd K, Sonntag C, Dillinger L, McKenna K. The impact of food allergy on the daily activities of children and their families. Ann Allergy Asthma Immunol. 2006;96:415-21.

17. Lebovidge JS, Stone KD, Twarog FJ, Raiselis SW, Kalish LA, Bailey EP, et al. Development of a preliminary questionnaire to assess parental response to children's food allergies. Ann Allergy Asthma Immunol. 2006;96:472-7.

18. DunnGalvin A, de BlokFlokstra BM, Burks AW, Dubois AE, Hourihane JO. Food allergy QoL questionnaire for children aged 0-12 years: content, construct, and cross-cultural validity. Clin Exp Allergy. 2008;38:977-86.

19. Mackenzie H, Roberts $G$, Van Laar D, Dean T. A new quality of life scale for teenagers with food hypersensitivity. Pediatr Allergy Immunol. 2012;23:404-11.

20. Mikkelsen A, Borres MP, Bjorkelund C, Lissner L, Oxelmark L. The food hypersensitivity family impact (FLIP) questionnaire-development and first results. Pediatr Allergy Immunol. 2013;24:574-81.

21. Winberg A, West CE, Strinnholm A, Nordstrom L, Hedman L, Ronmark E. Assessment of allergy to milk, egg, cod, and wheat in swedish schoolchildren: a population based cohort study. PLoS ONE. 2015. doi:10.1371/ journal.pone.0131804.

22. Ronmark E, Bjerg A, Perzanowski M, Platts-Mills T, Lundback B. Major increase in allergic sensitization in schoolchildren from 1996 to 2006 in northern Sweden. J Allergy Clin Immunol. 2009;124:357-63.

23. Bjerg A, Sandstrom T, Lundback B, Ronmark E. Time trends in asthma and wheeze in Swedish children 1996-2006: prevalence and risk factors by sex. Allergy. 2010;65:48-55.

24. Strinnholm A, Winberg A, West C, Hedman L, Ronmark E. Food hypersensitivity is common in Swedish schoolchildren, especially oral reactions to fruit and gastrointestinal reactions to milk. Acta Paediatr. 2014;103:1290-6.

25. Asher MI, Keil U, Anderson HR, Beasley R, Crane J, Martinez F, et al. International study of Asthma and Allergies in Childhood (ISAAC): rationale and methods. Eur Respir J. 1995;8:483-91.

26. Ravens-Sieberer U, the European KIDSCREEN Group. The KIDSCREEN Questionnaires - quality of life questionnaires for children and adolescents—handbook. Lengerich: Pabst Science Publisher; 2006.

27. Ravens-Sieberer U, Herdman M, Devine J, Otto C, Bullinger M, Rose M, et al. The European KIDSCREEN approach to measure quality of life and well-being in children: development, current application, and future advances. Qual Life Res. 2014;23:791-803.

28. Protudjer JL, Jansson SA, Middelveld R, Ostblom E, Dahlen SE, Arnlind MH, et al. Impaired health-related quality of life in adolescents with allergy to staple foods. Clin Transl Allergy. 2016;6:37.

29. Salvilla SA, Dubois AE, Flokstra-de Blok BM, Panesar SS, Worth A, Patel S, et al. Disease-specific health-related quality of life instruments for lgEmediated food allergy. Allergy. 2014;69:834-44.

30. Schunemann HJ, Akl EA, Guyatt GH. Interpreting the results of patient reported outcome measures in clinical trials: the clinician's perspective. Health Qual Life Outcomes. 2006;4:62.

31. Jansson SA, Heibert-Arnlind M, Middelveld RJ, Bengtsson UJ, Sundqvist AC, Kallstrom-Bengtsson I, et al. Health-related quality of life, assessed with a disease-specific questionnaire, in Swedish adults suffering from well-diagnosed food allergy to staple foods. Clin Transl Allergy. 2013;3:21.

32. Covaciu C, Bergstrom A, Lind T, Svartengren M, Kull I. Childhood allergies affect health-related quality of life. J Asthma. 2013;50:522-8.

33. Howe L, Franxman T, Teich E, Greenhawt M. What affects quality of life among caregivers of food-allergic children? Ann Allergy Asthma Immunol. 2014;113:69-74.

34. Lieberman JA, Weiss C, Furlong TJ, Sicherer M, Sicherer SH. Bullying among pediatric patients with food allergy. Ann Allergy Asthma Immunol. 2010;105:282-6.

35. Nwaru BI, Hickstein L, Panesar SS, Roberts G, Muraro A, Sheikh A, et al. Prevalence of common food allergies in Europe: a systematic review and meta-analysis. Allergy. 2014;69:992-1007.
36. Mackenzie H, Roberts G, Van Laar D, Dean T. Teenagers' experiences of living with food hypersensitivity: a qualitative study. Pediatr Allergy Immunol. 2010;21:595-602.

37. Gallagher M, Worth A, Cunningham-Burley S, Sheikh A. Strategies for living with the risk of anaphylaxis in adolescence: qualitative study of young people and their parents. Prim Care Respir J. 2012;21:392-7.

38. Berman AH, Liu B, Ullman S, Jadback I, Engstrom K. Children's quality of life based on the KIDSCREEN-27: child self-report, parent ratings and child-parent agreement in a Swedish random population sample. PLoS ONE. 2016. doi:10.1371/journal.pone.0150545.

39. DunnGalvin A, Koman E, Raver E, Frome H, Adams M, Keena A, et al. An examination of the Food Allergy Quality of Life Questionnaire performance in a countrywide American sample of children: cross-cultural differences in age and impact in the United States and Europe. J Allergy Clin Immunol Pract. 2016. doi:10.1016/j.jaip.2016.09.049.

40. Antolin-Amerigo D, Manso L, Caminati M, de la Hoz CaballerB, Cerecedo I, Muriel A, et al. Quality of life in patients with food allergy. Clin Mol Allergy. 2016;14:4.

41. Protudjer J, Jansson SA, Ostblom E, Arnlind MH, Bengtsson U, Dahlen SE, et al. Health-related quality of life in children with objectively diagnosed staple food allergy assessed with a disease-specific questionnaire. Acta Paediatr. 2015;104:1047-54.

42. Foucard T, Yman IM, Nordvall L. Reduced number of fatal and life-threatening reaction to food. Reporting by the medical profession has resulted in effective measures. Lakartidingen. 2005;102:3465-8.

43. Ostblom E, Egmar AC, Gardulf A, Lilja G, Wickman M. The impact of food hypersensitivity reported in 9-year-old children by their parents on health-related quality of life. Allergy. 2008;63:211-8.

44. Winberg A, West CE, Strinnholm A, Nordstrom L, Hedman L, Ronmark E. Milk allergy is a minor cause of milk avoidance due to perceived hypersensitivity among schoolchildren in Northern Sweden. Acta Paediatr. 2016;105:206-14

45. Le TM, Flokstra-de Blok BM, van Hoffen E, Lebens AF, Goossens NJ, Dubois $A E$, et al. Quality of life is more impaired in patients seeking medical care for food allergy. Int Arch Allergy Immunol. 2013;162:335-9.

46. Cavallo F, Zambon A, Borraccino A, Raven-Sieberer U, Torsheim T, Lemma $P$. Girls growing through adolescence have a higher risk of poor health. Qual Life Res. 2006:15:1577-85.

47. Di Rienzo T, D'Angelo G, D'Aversa F, Campanale MC, Cesario V, Montalto $M$, et al. Lactose intolerance: from diagnosis to correct management. Eur Rev Med Pharmacol Sci. 2013;17(2):18-25.

48. Skripak JM, Matsui EC, Mudd K, Wood RA. The natural history of IgEmediated cow's milk allergy. J Allergy Clin Immunol. 2007;120:1172-7.

49. Eigenmann PA, Caubet JC, Zamora SA. Continuing food-avoidance diets after negative food challenges. Pediatr Allergy Immunol. 2006;17:601-5.

50. Usai-Satta P, Scarpa M, Oppia F, Cabras F. Lactose malabsorption and intolerance: What should be the best clinical management? World J Gastrointest Pharmacol Ther. 2012;3:29-33.

51. Strinnholm A, Winberg A, Hedman L, Ronmark E, Lindh V. Reintroduction failure is common among adolescents after double-blind placebo-controlled food challenges. Acta Paediatr. 2016;106:282-7.

52. Strinnholm A, Brulin C, Lindh V. Experiences of double-blind, placebocontrolled food challenges (DBPCFC): a qualitative analysis of mothers' experiences. J Child Health Care. 2010;14:179-88.

53. Kallio P, Salmivesi S, Kainulainen H, Paassilta M, Korppi M. Parent-reported food allergy requiring an avoidance diet in children starting elementary school. Acta Paediatr. 2011;100:1350-3.

54. Flokstra-de Blok BM, van der Velde JL, Vlieg-Boerstra BJ, Oude Elberink JN, DunnGalvin A, Hourihane JO, et al. Health-related quality of life of food allergic patients measured with generic and disease-specific questionnaires. Allergy. 2010;65:1031-8.

55. Upton P, Lawford J, Eiser C. Parent-child agreement across child healthrelated quality of life instruments: a review of the literature. Qual Life Res. 2008;17:895-913. 